\title{
Performance Evaluation of Concrete using Marble Mining Waste
}

\author{
Kore Sudarshan Dattatraya and Vyas A. K. \\ Malaviya National Institute of Technology, Jaipur, Rajasthan-302017, India \\ e-mail: sudarshankore123@gmail.com, akvyas.ce@mnit.ac.in
}

\begin{abstract}
A huge amount waste (approximately 60\%) is generated during mining and processing in marble industries. Such waste can be best utilized in infrastructure development works. Coarse aggregate $75 \%$ by weight was replaced by aggregate obtained from marble mining waste. The impact of marble waste as a partial replacement for conventional coarse aggregate on the properties of concrete mixes such as workability, compressive strength, permeability, abrasion, etc. was evaluated. The test results revealed that the compressive strength was comparable to that of control concrete. Other properties such as workability of concrete increased, water absorption reduced by $17 \%$, and resistance to abrasion was marginally increased by $2 \%$ as compared to that of control concrete. Ultrasonic pulse velocity and FTIR results show improvement in quality of concrete with crushed marble waste. From the TGA analysis it was confirmed that, aggregate produced from marble waste shows better performance under elevated temperature than that of conventional aggregates.
\end{abstract}

Key words: concrete, marble mining waste, mechanical properties

\section{Introduction}

Concrete is the most widely used and important construction material in the world. There are various methods available for the design of concrete mixes. In general practice the concrete mixes are designed by using the conventional method prescribed by relevant codes or standards. Concept of packing density approach for the design of concrete mixes was introduced a couple of years back by Kwan et al [1], Fennis et al [2], Jeenu G. et al. [3], and B. Bhattacharjee et al. [4]. It aims at production of concrete with minimum voids. It is possible by combining the aggregate in a definite ratio resulting in maximum packing density. Cement paste content has to be at least equal to void content. Cement paste in excess of void content in certain volume becomes helpful in increasing workability. The reduced usage of cement content in concrete results in lesser emission of carbon di oxide.

A study conducted by Majella Anson et al. [5] reported that, by inclusion of an intermediate sized aggregate in the concrete mix, a reduction in cement paste up to $16 \%$ is possible. Marc Rached et al. [6] reported that, shape and size of aggregates affect both the packing density and required paste volume to achieve the desired strength and workability. Poorly shaped or 
poorly graded aggregates can increase the paste volume and this can be minimized by using the gap grading aggregates. De Larrard [7], reported that, workability and packing density can be improved by using gap graded aggregates. B. Bhattacharjee et al. [4] in their study reported that, the optimum packing density can be obtained by combining the coarse and fine aggregates in a definite ratio. They also reported that, the compressive strength obtained by packing density approach are comparable to that obtained from Bureau of Indian Standards (BIS) code method for a given water-cement ratio. The co-relation curves plotted between compressive strength vs. water-cement ratio and compressive strength vs paste content could be used to decide the water-cement ratio and paste content for specified grade of concrete in packing density method. Fennis et al. [2], in their study reported that, concrete mixes could be designed by using particle packing method and it is possible to reduce the cement content up to $50 \%$ and the $\mathrm{CO} 2$ emission was reduced by $25 \%$. A study by Wong and Kwan et al. [1], depicts the effect of blending cement with various supplementary materials like pulverized fly ash and condensed silica fume on packing density. He reported that the addition of ultrafine particles in the cement increases the packing density and addition of super plasticizer always increases the packing density of cementitious materials.

There are around 4000 marble mines and 1100 processing units operating in the state of Rajasthan [8]. These industries produce a lot of waste of marble in the form of powder / slurry and pieces of irregular size of stones during their processing operation. There is no proper way for disposal of this waste in the mining and processing areas which cause significant impact on the surrounding environment. It is thrown randomly on the roadsides or fields as seen in Figure 1.

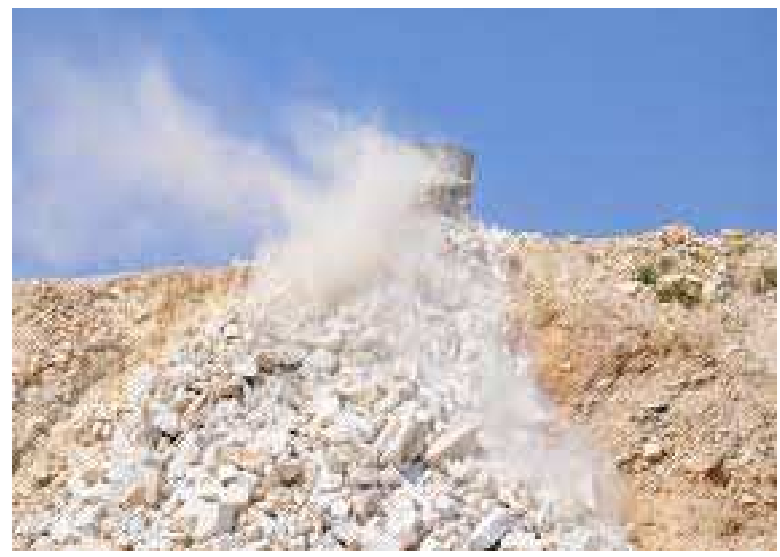

Figure 1: Marble waste dumped in open lands

H. Hebhoub et al [9] conducted studies on use of marble waste (0 to 100\%) in the form of fine aggregate and coarse aggregate in concrete with water-cement ratio of 0.5 . He reported that workability decreased with increase in replacement level for all the formulations. Compressive strength of concrete mix increases by $25 \%$ at $75 \%$ replacement of conventional coarse aggregate by marble aggregate. He also reported that an increase in compressive strength was $16.84 \%$ for mixes, prepared with $75 \%$ replacement of fine and coarse aggregate. In a study conducted by Antonio Andre et al [10], marble waste was used in different percentages (20\% to $100 \%)$ as replacement for conventional aggregates. It was reported that, workability of concrete mix decreased as the replacement level increased. With regard to compressive strength they reported that, concrete mixes showed downward trend with 
increasing incorporation ratio, but this decrease was considered almost insignificant with variations up to $10.3 \%$. In a study by Hanifi Binci et al [11], the marble waste was used as a $100 \%$ replacement for natural coarse aggregates by weight in concrete with a constant watercement ratio 0.4. It was reported that compressive strength, flexural strength, splitting tensile strength and Young's modulus of elasticity of concrete, prepared with (Ground Blast Furnace Slag) GBFS as fine aggregate and marble waste as coarse aggregate was $3 \%$ and $6 \%$, respectively, higher than that of concrete with river sand as fine aggregate and marble waste as coarse aggregate. In a study conducted by Kore et al [12] reported, the impact of partial replacement of conventional coarse aggregates by marble mining waste in different percentages (0 to 100\%) in low strength concrete designed as per Bureau of Indian Standards (BIS) code method [13]. They reported that, the workability of all the concrete mixes increased with increase in replacement level. The compressive strength of the concrete mixes increased by $35 \%$ at $80 \%$ replacement level.

In the present study, the concrete mix was designed by the particle packing density approach. The physical and mechanical properties of concrete mixes such as workability, compressive strength, permeability, resistance to abrasion etc. were evaluated.

\section{Experimental study}

\subsection{Characterization of materials}

Portland Pozzolana cement used in this study fulfills the requirement of BIS: 1489-part 11991 [14]. The initial and final setting time, consistency and compressive strength of cement are shown in Table 1. The sand used in this study conforms to grading zone II as per BIS: 383-1960 [15]. The properties of sand are presented in Table 2. The conventional coarse aggregate used in this study crushed coarse surface and conforms to BIS: 383-1960 [15]. Marble Mining Waste used in this study was crushed in to crusher to obtain desired gradation of coarse aggregate. The surface of the marble aggregate is smooth whereas the surface of the conventional aggregate is rough textured. The Specific gravity and water absorption of coarse aggregates are presented in Table 2. The nominal maximum size of coarse aggregate used was $20 \mathrm{~mm}$. The particle size distribution of coarse aggregate is given in Table 3 . The chemical composition of conventional and marble coarse aggregate are presented in Table 4. To achieve the desired slump of $75 \mathrm{~mm}$, a third generation polycarboxylate based super-plasticizer Rheobuild 522 ND conforming to BIS: 9103-1999 [16] was used.

Table 1: Physical-mechanical properties of cement

\begin{tabular}{|c|c|}
\hline Initial Setting Time & 47 minute \\
\hline Final setting time & 483 minute \\
\hline Compressive strength & \\
\hline 3 days & $20 \mathrm{MPa}$ \\
\hline 7 days & $24 \mathrm{MPa}$ \\
\hline 28 days & $39 \mathrm{MPa}$ \\
\hline consistency & $27 \%$ \\
\hline Specific gravity & $3.11{\mathrm{~g} . \mathrm{cm}^{-3}}$ \\
\hline
\end{tabular}


Table 2: Physical properties of aggregates

\begin{tabular}{|c|c|c|c|c|}
\hline $\begin{array}{c}\text { Aggregate } \\
\text { Type }\end{array}$ & $\begin{array}{c}\text { Specific } \\
\text { gravity } \\
\left(\mathrm{g} . \mathrm{cm}^{-3}\right)\end{array}$ & $\begin{array}{c}\text { Water Absorption } \\
(\%) \text { by weight }\end{array}$ & Grading Zone & $\begin{array}{c}\text { Los Angeles } \\
\text { Abrasion Value } \\
(\%)\end{array}$ \\
\hline $\begin{array}{c}\text { Conventional } \\
\text { Coarse } \\
\text { aggregate }\end{array}$ & 2.78 & 0.54 & $\begin{array}{c}\text { As per Table } 2 \text { of } \\
\text { BIS 383 }\end{array}$ & 25.88 \\
\hline Fine Aggregate & 2.66 & 2.0 & $\begin{array}{c}\text { Zone II As per Table } \\
\text { 4 of BIS 383 }\end{array}$ & - \\
\hline $\begin{array}{c}\text { Marble coarse } \\
\text { Aggregate }\end{array}$ & 2.88 & 0.05 & $\begin{array}{c}\text { As per Table 2 of IS } \\
383\end{array}$ & 34.87 \\
\hline
\end{tabular}

Table 3: Particle size distribution of aggregates

\begin{tabular}{|c|c|c|c|}
\hline $\begin{array}{c}\text { Sieve size } \\
(\mathrm{mm})\end{array}$ & $\begin{array}{c}\text { Percentage Passing of } \\
\text { Marble Aggregate }\end{array}$ & $\begin{array}{c}\text { Percentage Passing of } \\
\text { Natural Aggregate }\end{array}$ & $\begin{array}{c}\text { Percentage passing of } \\
\text { fine aggregate }\end{array}$ \\
\hline 40 & 100 & 100 & - \\
\hline 20 & 95.28 & 95 & - \\
\hline 10 & 37.28 & 54.88 & 100 \\
\hline 4.75 & 0.14 & 6.8 & 95.45 \\
\hline $2.36 \mathrm{~mm}$ & - & - & 89.25 \\
\hline $1.18 \mathrm{~mm}$ & - & - & 79.45 \\
\hline $600 \mu$ & - & - & 59.4 \\
\hline $300 \mu$ & - & - & 14.35 \\
\hline $150 \mu$ & - & - & 1.2 \\
\hline
\end{tabular}

Table 4: Chemical compositions as percentage of oxides in marble waste and natural aggregate

\begin{tabular}{|c|c|c|}
\hline Component & Marble Waste Aggregate (\%) & Natural Aggregate (\%) \\
\hline $\mathrm{LOI}$ & 45.07 & 5.08 \\
\hline $\mathrm{SiO}_{2}$ & 3.75 & 53.70 \\
\hline $\mathrm{CaO}$ & 33.12 & 4.83 \\
\hline $\mathrm{MgO}$ & 17.91 & 2.01 \\
\hline $\mathrm{Fe}_{2} \mathrm{O}_{3}$ & 10.66 \\
\hline $\mathrm{Al}_{2} \mathrm{O}_{3}$ & 0.13 & Nil \\
\hline Sulphate content & Traces & Nil \\
\hline
\end{tabular}

\subsection{Concrete mix proportioning}

Coarse aggregate was taken as mix of $75 \%$ marble aggregate and $25 \%$ conventional aggregate as per best results obtained by the authors in trial mixes. The mixture proportions of concrete designed by packing density approach are given in Table 5. All the concrete mixes were prepared by using a constant water-cement ratio of 0.45 . The concrete mixes were prepared by taking cement paste content $10 \%$ in excess of void content. Before the addition of water, the dry concrete mixes were blended for 5 minutes to achieve a thorough mix in a 160 lit capacity mixer. 
Table 5: Mix proportion of control concrete

\begin{tabular}{|c|c|c|c|c|c|c|c|c|}
\hline \multirow{3}{*}{ Mix } & \multirow{3}{*}{$\begin{array}{l}\text { Paste content in } \\
\text { excess of voids } \\
\text { (\%) }\end{array}$} & \multirow{3}{*}{$\begin{array}{l}\text { Water } \\
\text { (lit.) }\end{array}$} & \multirow{3}{*}{$\begin{array}{l}\text { Cement } \\
(\mathrm{kg})\end{array}$} & \multirow{3}{*}{$\begin{array}{l}\text { sand } \\
(\mathrm{kg})\end{array}$} & \multicolumn{4}{|c|}{ Coarse Aggregate (kg) } \\
\hline & & & & & \multicolumn{2}{|c|}{$\begin{array}{c}\text { Natural } \\
\text { Aggregate }\end{array}$} & \multicolumn{2}{|c|}{$\begin{array}{c}\text { Marble } \\
\text { Aggregate }\end{array}$} \\
\hline & & & & & $20 \mathrm{~mm}$ & $10 \mathrm{~mm}$ & $20 \mathrm{~mm}$ & $\begin{array}{c}10 \\
\mathrm{~mm}\end{array}$ \\
\hline $\mathrm{C} 1$ & 10 & 156.66 & 348.13 & 800.44 & 720.39 & 480.26 & - & - \\
\hline $\mathrm{C} 2$ & 10 & 154.34 & 342.98 & 805.35 & 181.2 & 120.8 & 543.61 & 362.4 \\
\hline
\end{tabular}

Note: Mix designated by $\mathrm{C} 1$ shows control mix and mix designated by $\mathrm{C} 2$ shows concrete mix containing $75 \%$ marble aggregate and $25 \%$ conventional coarse aggregate both the concrete mixes are designed by Packing Density approach.

\subsection{Sample preparation and test methods}

The ingredients of concrete were mixed in a mixer and cubes of size $150 \mathrm{~mm} \times 150 \mathrm{~mm} \times 150$ $\mathrm{mm}$ were cast to determine the compressive strength and permeability of test specimens. All the specimens were de-molded at the age of $24 \pm 1 \mathrm{~h}$ and thereafter were cured in the water tank at room temperature up to the specified age of the test. The slump cone test on freshly prepared concrete mix was carried out as per BIS 1199 [17] for measuring workability of concrete. Compressive strength of concrete specimens was determined at 7 days, 28 days, 90 days and 180 days curing age as per BIS: 516-1959 [18]. To assess the porosity in concrete, water permeability test was conducted as per German standard DIN -1048 part 5-1991 [19]. Test specimens $100 \mathrm{~mm} \times 100 \mathrm{~mm} \times 100 \mathrm{~mm}$ cubes were cast for determination of water absorption test. This test was conducted according to BIS 15658:2006 [20]. In order to assess homogeneity and quality of concrete the ultra-sonic pulse velocity test was conducted according to BIS 13311 (Part 1): 1992 [21]. Resistance to abrasion was measured in terms of depth of wear of concrete under standard testing conditions. It was performed according to BIS 1237: 1980 [22] on test specimens of $100 \mathrm{~mm}$ concrete cubes. The Fourier transform infrared spectroscopy (FTIR) analysis was used to separate the components of a mixture and to know the functional group. The Thermo Gravimetric Analysis (TGA) was carried out to study the behavior of concrete under elevated temperature.

\section{Results and discussion}

\subsection{Workability}

The variation in the slump values of both the mixes is shown in Figure 3. From the results it can be seen that, the workability of concrete mix C2 was $100 \mathrm{~mm}$. That is approximately $10 \%$ more than that of conventional aggregate mix $\mathrm{C} 1$. This increase in the value of slump in mix $\mathrm{C} 2$ was due to presence of round shaped marble aggregates. The round shaped aggregates are more workable than that of angular shaped aggregates as reported by Gambhir [23]. The water absorption of marble aggregate was also less than that of conventional coarse aggregate resulting in availability of adequate water for lubrication. 


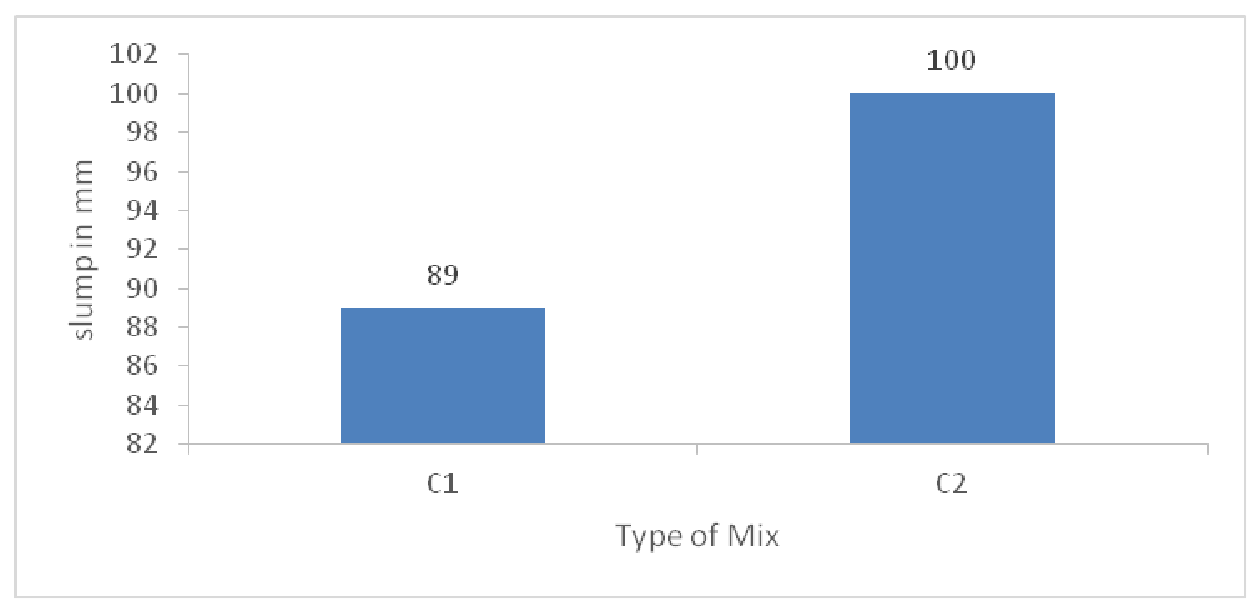

Figure 3: Workability of concrete mix

The title page must give the title of the paper, all authors with their affiliations and up to five keywords. The title page shall appear as the first page of this document. The body of the text must start after the key words.

\subsection{Density}

The results of the variation in density of concrete mix are presented in Figure 4. From the results it can be seen that, the density of concrete mix increases from $2400 \mathrm{~kg} / \mathrm{m}^{3}$ to 2420 $\mathrm{kg} / \mathrm{m}^{3}$. The increase in the density of concrete mix C2 was due to higher specific gravity of marble aggregate.

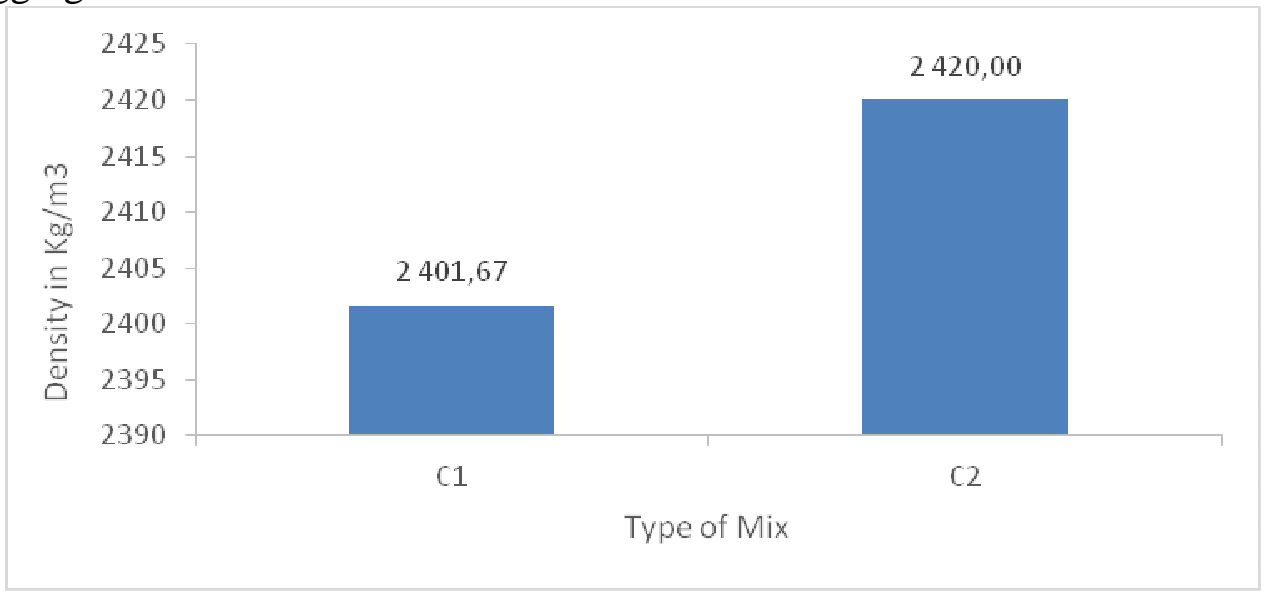

Figure 4: Density of concrete mix

\subsection{Water Absorption and Permeability}

The variation in water absorption of concrete specimens is shown in Figure 5. The results show that, the water absorption of mix $\mathrm{C} 2$ was $17 \%$ less than that of control mix. The decrease in water absorption was due to less water absorption by marble aggregate as compared to conventional coarse aggregate. 


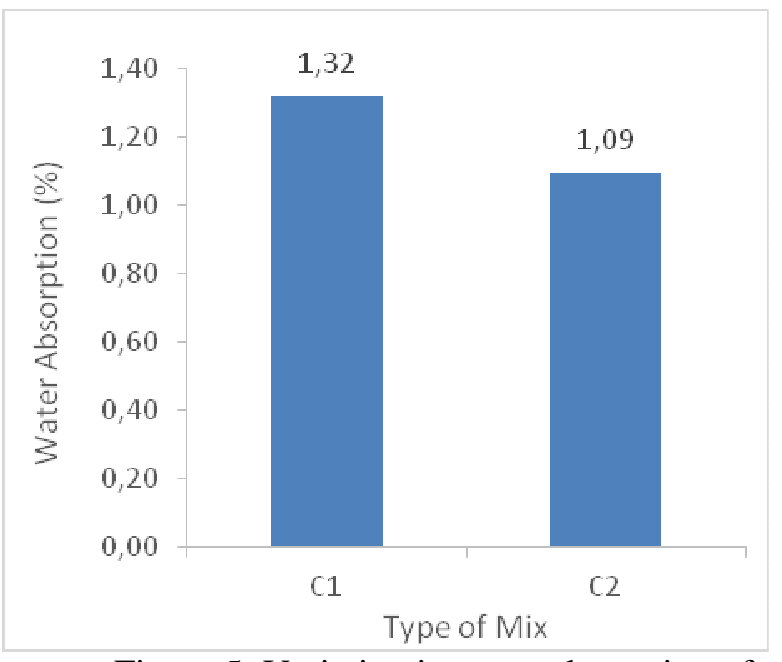

Figure 5: Variation in water absorption of concrete

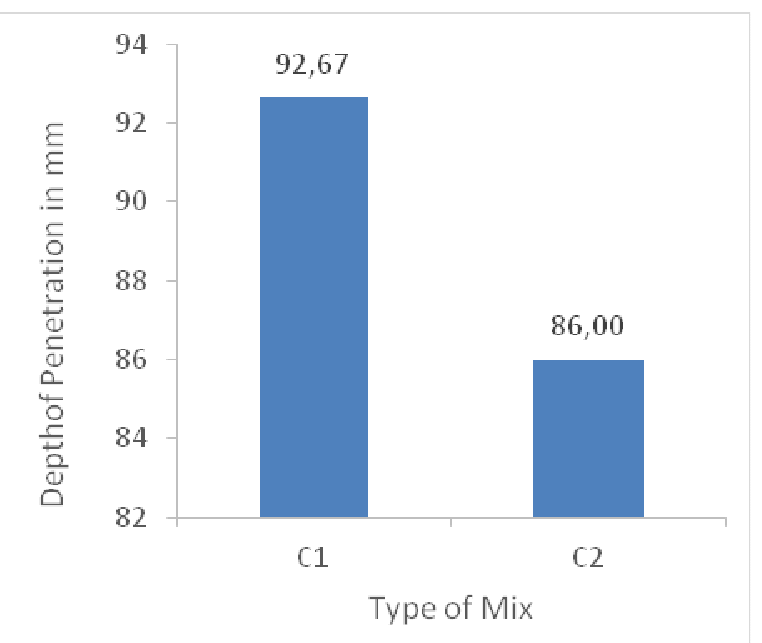

Figure 6: Variation in water permeability of concrete

The variations in the depth of water penetration in concrete specimens are shown in Figure 6. From the figure, it can be seen that the depth of penetration of water of concrete mix $\mathrm{C} 2$ was reduced by $7 \%$ as compared to that of concrete mix $\mathrm{C} 1$. The permeability of concrete depends on various factors; one of the major factors is the interconnectivity of pores in the concrete. The reduction in permeability was due to the reduction in pores in the concrete mix $\mathrm{C} 2$.

\subsection{Compressive strength}

The variations in the compressive strength of concrete mixes under different curing ages are shown in Figure 7. The reduction in compressive strength of concrete mix C2 was $4.5 \%$ at 7 days, $5.43 \%$ at 28 days, $3.41 \%$ at 90 days and $9.64 \%$ at 180 days as compared to that of control mix. But this reduction is considered as insignificant. However this is due to presence of inadequate fractions below $10 \mathrm{~mm}$ in marble aggregate. Another possible reason is round shape of marble aggregate as compared to conventional coarse aggregate. Both the factors are responsible for fall of compressive strength in $\mathrm{C} 2 \mathrm{mix}$.

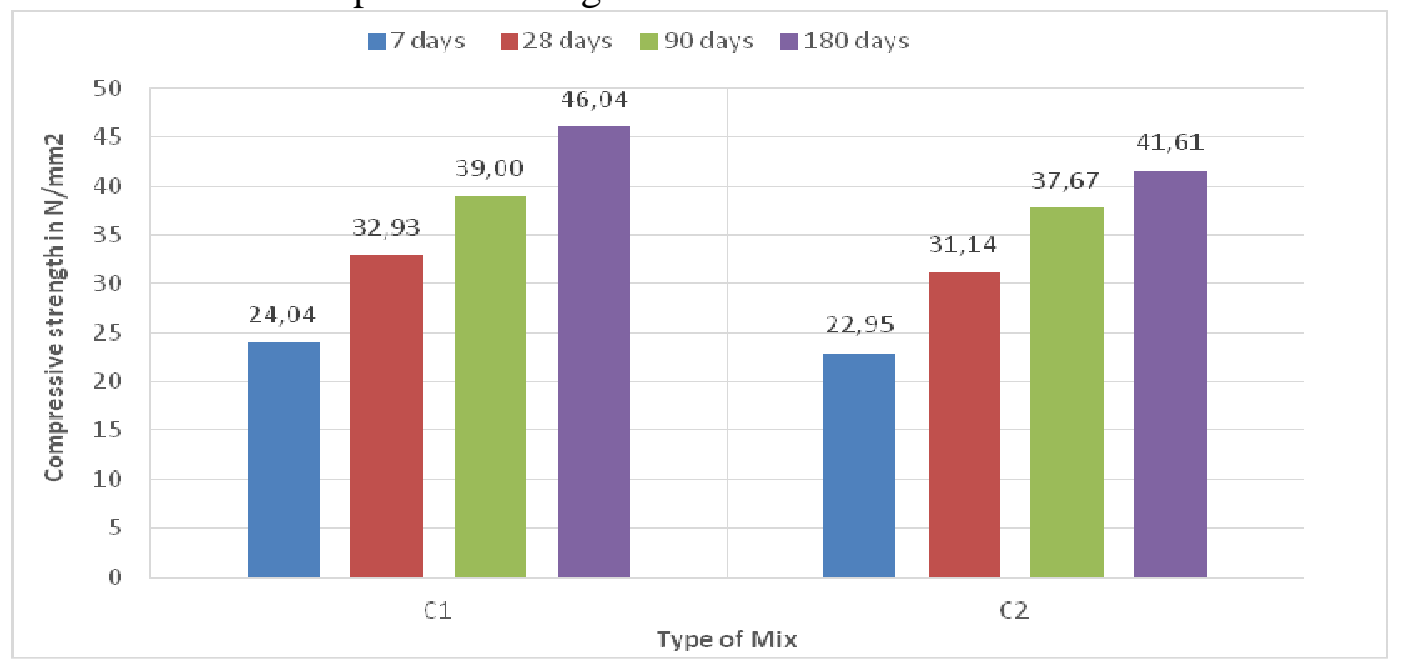

Figure 7: Variation in compressive strength of concrete 


\subsection{Ultrasonic Pulse Velocity}

The results of the Ultra Sonic Pulse velocity values are presented in Figure 8. The results of this test show that, the values of pulse velocity increases from $5.238 \mathrm{~m} / \mathrm{sec}$ to $5.499 \mathrm{~m} / \mathrm{sec}$. This increase in the value of mix C2 indicates better quality in terms of density, homogeneity and uniformity. Both the mixes satisfy the minimum requirement of $4.5 \mathrm{~m} / \mathrm{sec}$ for good concrete mixes.

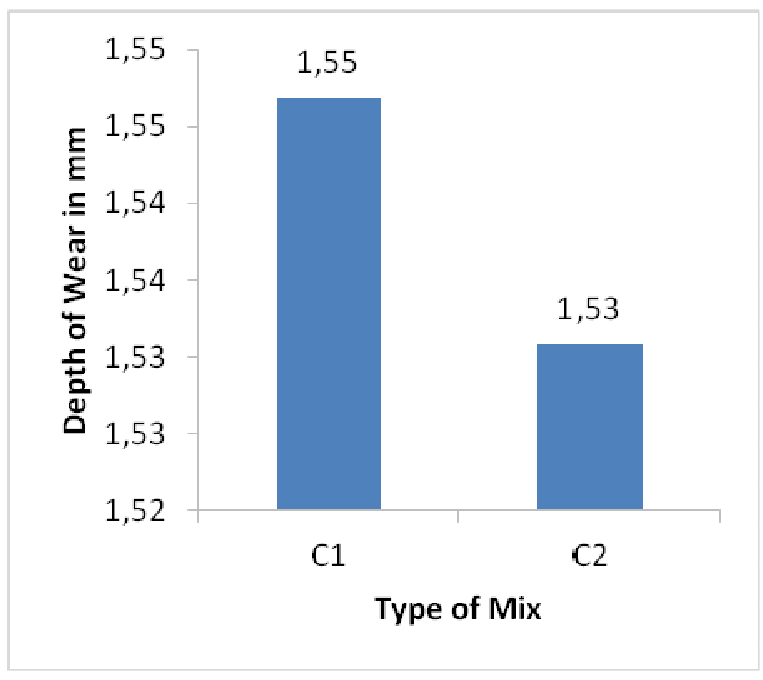

Figure 8:Variation in ultrasonic pulse velocity of concrete

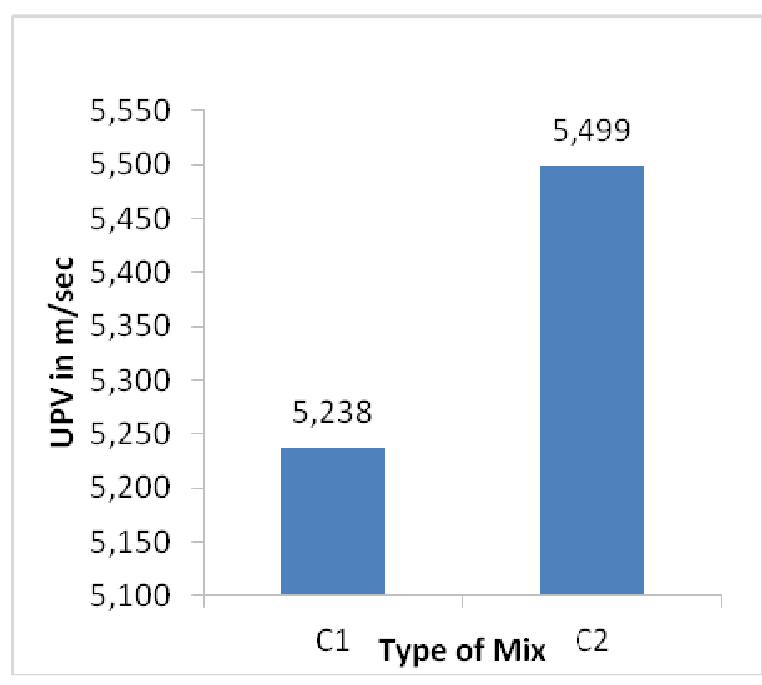

Figure 9: Variation in abrasion resistance of concrete

\subsection{Abrasion resistance}

The resistance to abrasion was measured in terms of depth of wear of the concrete specimens. Figure 9 shows the average depth of wear of the concrete specimens. The results show that the abrasion resistance of mix C2 increased by approximately $2 \%$ as compared to that of control mix. The presence of carbonate content in marble aggregates improves the bond between the aggregate and cement paste. Thus resulting in the more dense and compact structure of the concrete. The marble aggregate is hard as compared to that of conventional aggregate. This is possible reason for marginal improvement in resistance to abrasion of $\mathrm{C} 2$ mixes.

\subsection{Fourier Transform Infrared spectroscopy (FTIR)}

Fourier Transform Infrared spectroscopy is a powerful tool for the determination of molecular structure. IR spectroscopy allows us to deduce the functional groups that are present and absent in a molecule. Infrared spectroscopy involves absorption of infrared photons, which changes the bond vibrational state of the molecule. The results of the analysis done by Infrared spectroscopy are shown in Figure 10(a) and Figure 10(b). 


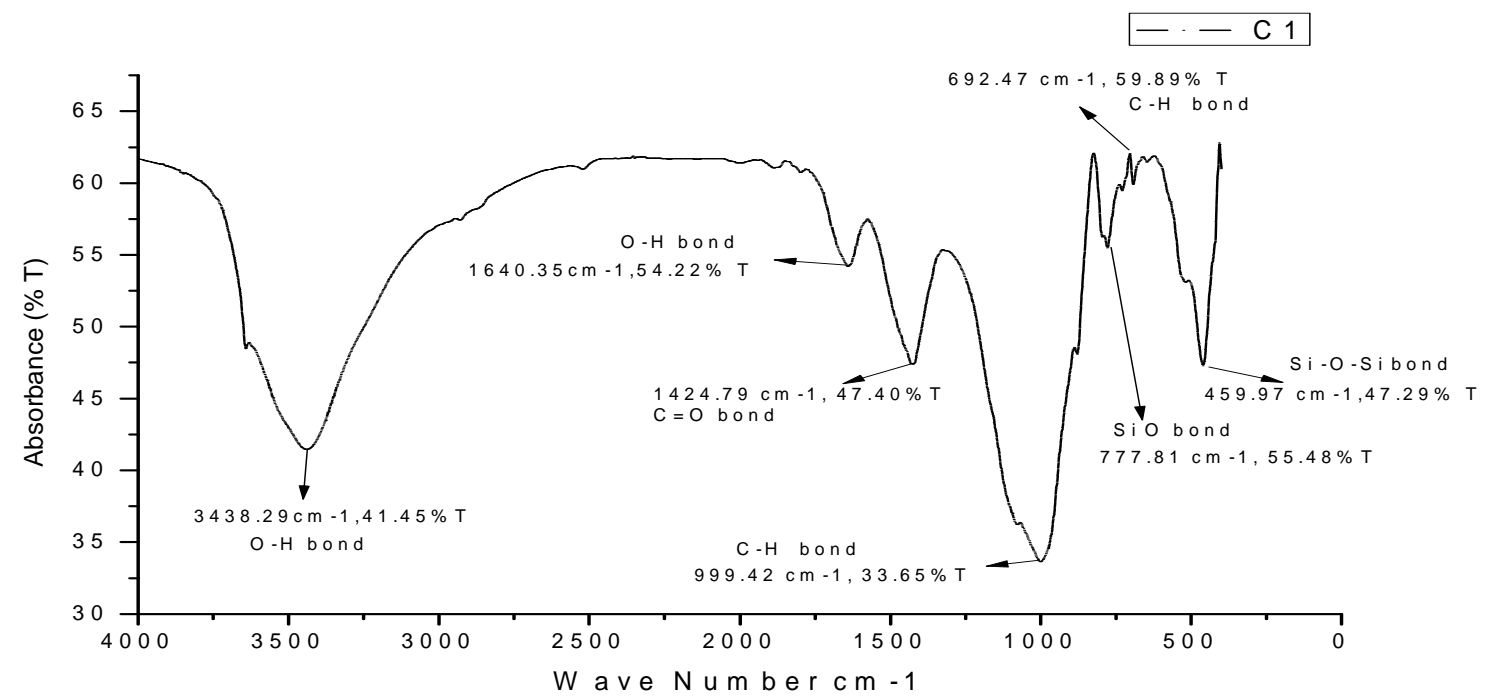

Figure 10(a): FTIR for control concrete

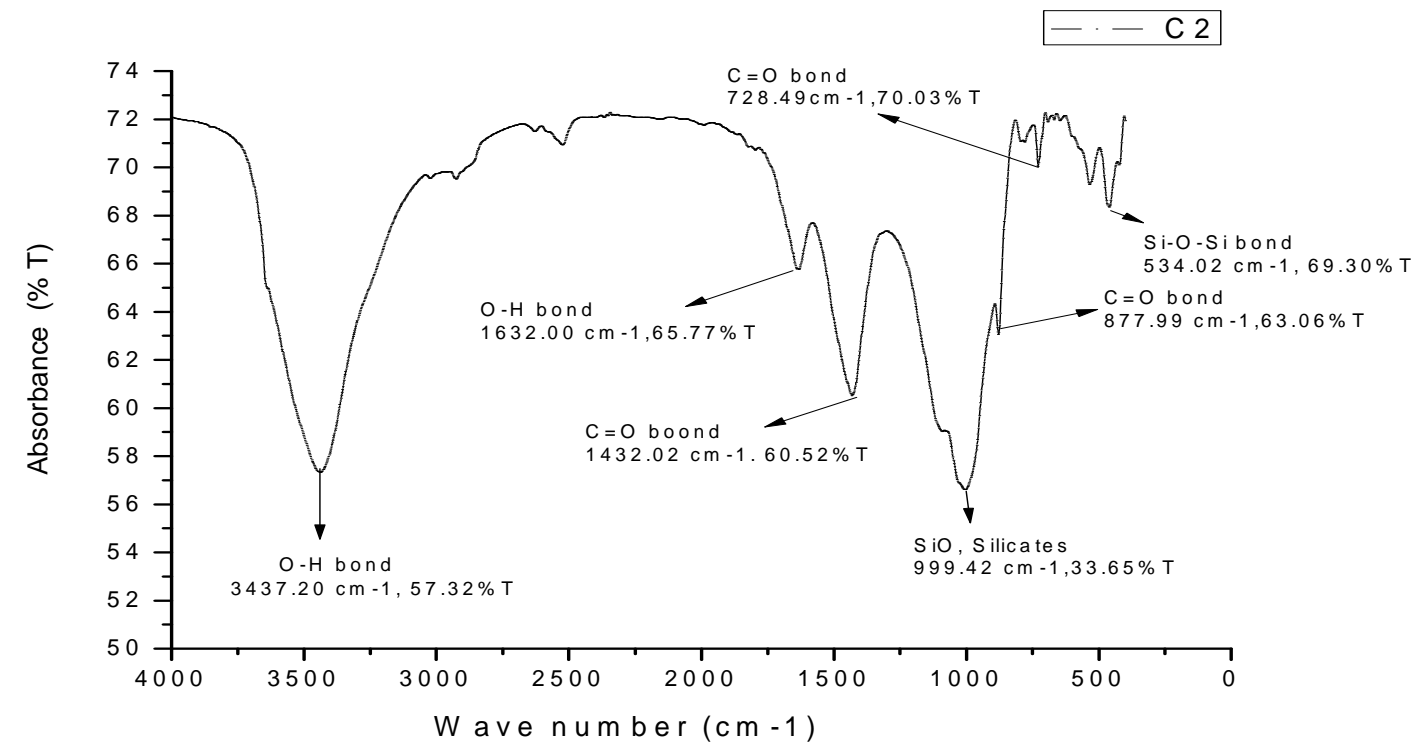

Figure 10(b): FTIR for concrete containing $75 \%$ marble aggregate

The FTIR spectra measured for the control concrete, concrete containing $75 \%$ marble aggregates and Table 6 summarize the main absorbance peak assignment for the FTIR spectra. 
Table 6: Assignment of the main FTIR absorbance peaks

\begin{tabular}{|c|c|c|c|c|}
\hline Wave number & Functional group & Assigned to & Bond Type & Refs. \\
\hline $1641,1632,3000-3750$ & $\mathrm{O}-\mathrm{H}$ & $\mathrm{Ca}(\mathrm{OH})_{2}$ & Strong & {$[24],[25]$} \\
\hline $710,872,1410,1324-1576$ & $\mathrm{C}=\mathrm{O}$ & $\mathrm{CaCO}_{3}$ & Very Strong & {$[25]$} \\
\hline $777,797,852,890-1079$ & $\mathrm{Si}-\mathrm{O}$ & $\mathrm{C}-\mathrm{S}-\mathrm{H}$ & Strong & {$[24],[25]$} \\
\hline $450-650$ & $\mathrm{Si}-\mathrm{O}-\mathrm{Si}$ & $\mathrm{SiO}_{2}$ & Strong & {$[25]$} \\
\hline
\end{tabular}

From the above analysis it was observed that, the presence of the compound such as calcium hydroxide, calcium silicate hydrate and quartz is confirmed in both the concrete mixes. The peaks obtained for calcium carbonate in the concrete mix $\mathrm{C} 2$ are more as compared to that of control mix. The presence of calcium carbonate in marble aggregate exhibits very strong bond as compared to that of conventional aggregates. As the Heboub et al.[9] reported that, the concrete containing marble aggregates improves the aggregates- cement paste bond due to excessive presence of carbonate content in marble aggregates.

\subsection{Thermo gravimetric analysis}

Thermo gravimetric analysis shows the dehydration, decomposition and oxidation of a sample with time and temperature. The TGA analysis was carried out on the powdered sample of concrete specimens. The result of the analysis is shown in Figure 11.

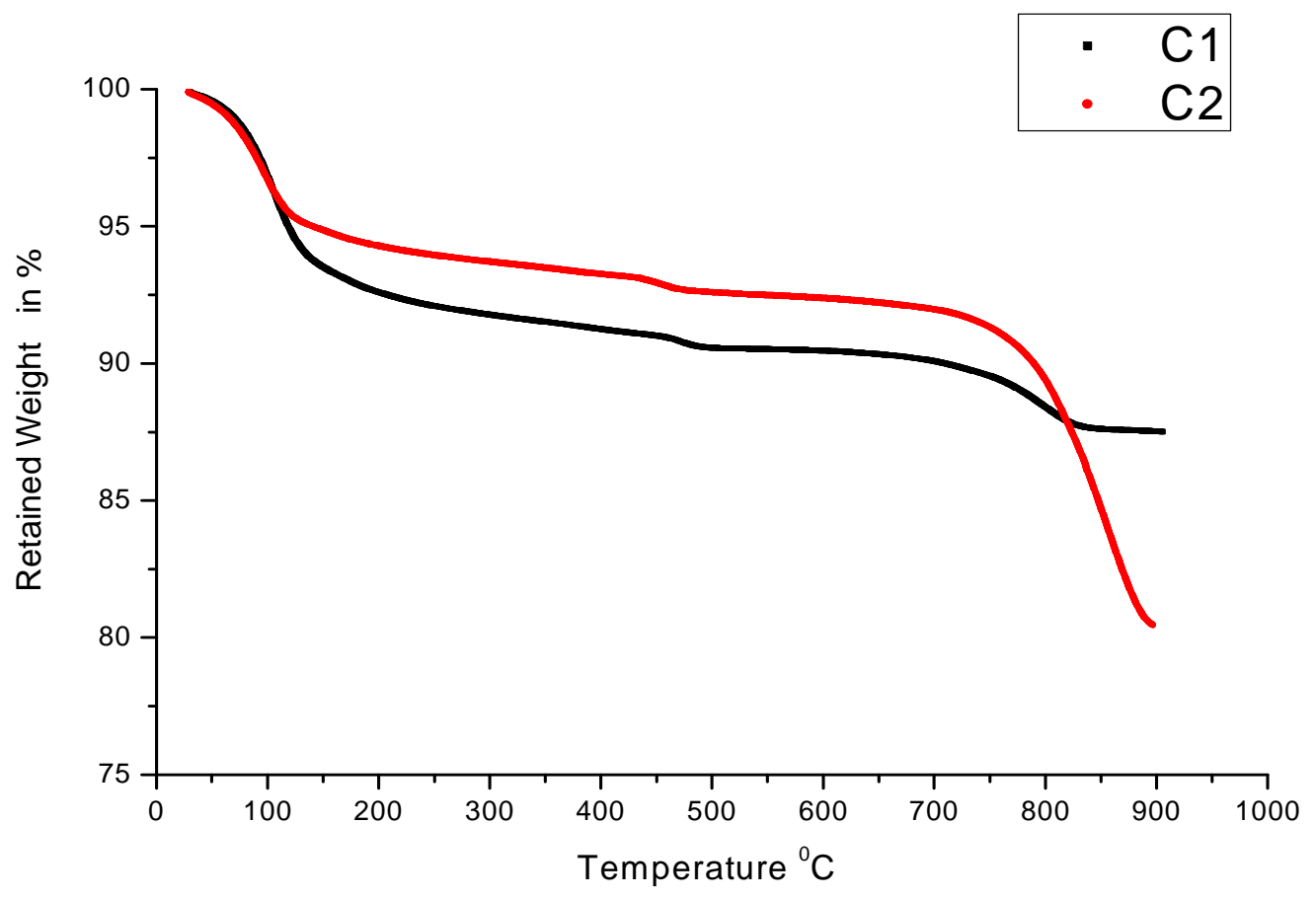

Figure 11: Thermo gravimetric analysis of concrete mixes $\mathrm{C} 1$ and $\mathrm{C} 2$ 
The first endothermic peak was observed at $110^{\circ} \mathrm{C}$, due to evaporation of free water molecules present in the concrete mix $\mathrm{C} 1$ and $\mathrm{C} 2$, respectively and dehydration of cement paste. The second endothermic peak was observed at $460^{\circ} \mathrm{C}$ i.e. a calcium hydroxide peak. The third endothermic peak was observed at $820^{\circ} \mathrm{C}$, due to dehydration of C-S-H gel. Generally the thermal decomposition of calcium hydroxide takes place due to decomposition of carbonate phases above $600^{\circ} \mathrm{C}$ for all specimens. In the concrete mix $\mathrm{C} 2$, thermal decomposition of carbonates was less than that of control mix. This was due to the presence of dolomite and calcite minerals in marble aggregates as seen in XRD analysis in Figure 11 (b). The mass changes in concrete mix $\mathrm{C} 1$ are $-4.2 \%,-9.04 \%,-12.09 \%,-12.46 \%$ and for concrete mix $\mathrm{C} 2$ are $-3.4 \%,-7.09 \%,-11.6 \%,-19.42 \%$ at temperatures of $110^{\circ} \mathrm{C}, 460^{\circ} \mathrm{C}, 820^{\circ} \mathrm{C}$ and $900^{\circ} \mathrm{C}$ respectively. The concrete containing marble aggregate (mix $\mathrm{C} 2$ ) shows lower rate of loss of mass up to a temperature of approximately $800^{\circ} \mathrm{C}$ as compared to that of control concrete.

\section{Conclusions}

In this study the impact of marble aggregate on the mechanical properties of concrete was studied. From the results it can be concluded that,

1. The workability of the concrete mix increased due to partial replacement of conventional coarse aggregate by marble aggregate.

2. The compressive strength of the concrete mix containing marble aggregates is nearly equal to that of control mix.

3. The water absorption of the mix containing marble aggregate was reduced by $17 \%$ and permeability reduced by $7 \%$, which is sign for improvement in durability performance of concrete.

4. The Ultra Sonic pulse velocity values show that, the partial replacement of conventional coarse aggregate by marble aggregate results in dense, homogeneous and uniform structure of concrete.

5. The resistance to abrasion shows similar results as that of control mix.

6. From the FTIR analysis, it was confirmed that, Marble aggregates exhibit stronger bond as compared to that of conventional aggregate.

7. Thermo gravimetric analysis reveals performance of concrete with marble waste was better than control concrete up to a temperature of $800^{\circ} \mathrm{C}$

The above results indicate that, the marble aggregate can be used to improve the mechanical properties of concrete. However, the behavior of such concrete in adverse environment is also under progress as part of comprehensive study.

\section{References}

[1] K.H. Kwan, H.H.C. Wong, Packing density of cementitious materials: part 2-packing and flow of OPC + PFA + CSF, Mater. Struct. 41 (2008) 773-784. doi:10.1617/s11527-007-9281-6.

[2] S. A. M. Fennis, J.C. Walraven, Using particle packing technology for sustainable concrete mixture design, Heron. 57 (2012) 73-101.

[3] G. Jeenu, P. Vinod, L. Mangal, Packing characteristics of aggregates for high performance concrete, Int. J. Earth Sci. Eng. 5 (2012) 1424-1431.

[4] N. Raj, S. G Patil, B. Bhattacharjee, Concrete Mix Design By Packing Density Method, IOSR J. Mech. Civ. Eng. 11 (2014) 34-46. doi:10.9790/1684-11213446. 
[5] M. Anson-cartwright, Optimization of Aggregate Gradation Combinations to Improve Concrete Sustainability Optimization of Aggregate Gradation Combinations to Improve Concrete Sustainability, (2011).

[6] and E.K. Marc Rached, David Fowler, Use of Aggregates to Reduce Cement Content in Concrete, (2010).

[7] F. de Larrard, Concrete optimisation with regard to packing density and rheology, 3rd RILEM Int. Symp. Rheol. Cem. Suspens. such as Fresh Concr. Fr. (2009). http://hal.archivesouvertes.fr/hal-00595686/.

[8] MSME Developement Institute Govt. of Indian, Status report on commercial utilization of marble slurry in Rajasthan., 2009.

[9] H. Hebhoub, H. Aoun, M. Belachia, H. Houari, E. Ghorbel, Use of waste marble aggregates in concrete, Constr. Build. Mater. 25 (2011) 1167-1171. doi:10.1016/j.conbuildmat.2010.09.037.

[10] A. André, J. De Brito, A. Rosa, D. Pedro, Durability performance of concrete incorporating coarse aggregates from marble industry waste, J. Clean. Prod. 65 (2014) 389-396. doi:10.1016/j.jclepro.2013.09.037.

[11] H. Binici, T. Shah, O. Aksogan, H. Kaplan, Durability of concrete made with granite and marble as recycle aggregates, J. Mater. Process. Technol. 208 (2008) 299-308. doi:10.1016/j.jmatprotec.2007.12.120.

[12] S.D. Kore, A.K. Vyas, Impact of Marble Waste as Coarse Aggregate on properties of lean cement concrete, Case Stud. Constr. Mater. 4 (2016) 85-92. doi:10.1016/j.cscm.2016.01.002.

[13] R.G. For, C.M.I.X. Design, Bureau of Indian Standards (BIS). Recommended Guidelines for Concrete Mix Design Tile IS:10262-1982, New Delhi, India., 1982 (1999).

[14] IS 1489 (part-1) 1991, Bureau of Indian Standards (BIS). Specification for Portland pozzolana cement- IS:1489(Part-1)-1991, New Delhi, India., (1991).

[15] Bureau of Indian Standards (BIS). Specification for coarse and fine aggregates from natural sources for concrete. IS:383, New Delhi, India; 1970., Building. (1997).

[16] M. Kisan, S. Sangathan, J. Nehru, S.G. Pitroda, Bureau of Indian Standards (BIS). Specification for Concrete Admixture IS:9103-1999, New Delhi, India., (1999).

[17] M.O.F. Sampling, A.O.F. Concrete, Bureau of Indian Standards (BIS). Specification for Methos of Sampling and Analysis of concrete, BIS:1199-1659,New Delhi, India, 1959 (1999).

[18] M. Of, T. For, S.O.F. Concrete, Bureau of Indian Standards Specification for Methods of Tests for Strength of ConcreteIS:516-1959, Is 516. 1959 (2002).

[19] German Standard for determination of Permeability of Concrete.-DIN-1048, (1991) 1-7.

[20] W. Finishing, Bureau of Indian Standards (BIS). Specification for Precast Cocrete Blocks For Paving, BIS:15658-2006, (2006).

[21] I. Standard, Bureau of Indian Standards (BIS). Specification for Non-Destructive testing of Concrete IS:13311(Part-2)-1992, New Delhi, India., (1999).

[22] S. For, C. Concrete, F. Tiles, Bureau of Indian Standards (BIS). Specification for Cement Concrete Flooring Tile IS:1237, New Delhi, India; 1980., Public Work. 1980 (2001).

[23] M.L. SHETTY, M.S., Gambhir, Concrete Technology: Theory and Practice, 2013. doi:10.1007/s13398-014-0173-7.2. 
[24] Z. Song, X. Xue, Y. Li, J. Yang, Z. He, S. Shen, L. Jiang, W. Zhang, L. Xu, H. Zhang, J. Qu, W. Ji, T. Zhang, L. Huo, B. Wang, X. Lin, N. Zhang, Experimental exploration of the waterproofing mechanism of inorganic sodium silicate-based concrete sealers, Constr. Build. Mater. 104 (2016) 276-283. doi:10.1016/j.conbuildmat.2015.12.069.

[25] M. Horgnies, P. Willieme, O. Gabet, Influence of the surface properties of concrete on the adhesion of coating: Characterization of the interface by peel test and FT-IR spectroscopy, Prog. Org. Coatings. 72 (2011) 360-379. doi:10.1016/j.porgcoat.2011.05.009. 
$\underline{\text { Kore Sudarshan Dattatraya and Vyas A. K. }}$ 